\title{
Helen Salisbury: The confident gatekeeper
}

\author{
Helen Salisbury GP \\ Oxford
}

One of the roles assigned to GPs is that of "gatekeeper" to the NHS. We are, according to one interpretation, the barrier that holds back a mass of patients who might otherwise swamp hospital clinics with an unsorted array of ill defined symptoms. Rejecting this caricature, we are better seen as experts who can treat most ailments and prevent many more, referring on to our hospital colleagues only those patients who need specialist investigation or surgery.

However we view it, GPs are credited in this role as being a source of cost effectiveness in the NHS. Investigating, diagnosing, and treating patients in primary care is far cheaper than in hospital. And patients who do go to hospital have a higher chance of accessing the correct department first time around than in health systems without primary care. ${ }^{12}$

There is a risk, however, that patients who want to see a specialist feel thwarted by this system, believing that they must fight for their right to be referred. They regard the GP as an obstacle standing in the way of access to the specialist opinion they need. Schemes that reward general practices for reducing their referrals make it much harder for us to gain patients' trust and confidence, and it's sometimes necessary to be explicit that decisions about referrals are being made on purely clinical grounds. ${ }^{3}$

The confidence with which I offer my diagnosis and suggested treatment will often determine whether I can convince the patient to follow my advice. If I don't inspire confidence it's likely that one of my GP colleagues will be seeing this patient in a few days, with the same request.

Patients often come for reassurance: they've noticed a lump—what does it mean? Is it serious? I may be completely confident that it's a reactive lymph node associated with a minor and self limiting viral infection, but my patient will not be reassured if I sound vague or doubtful.

Sometimes my attempts to reassure are ineffective because I haven't really listened and found out what the patient is worried about. I might guess that the man with headache is worried about a brain tumour or that the parent of a child with recurrent infections is worried about leukaemia, but I won't know unless I ask. When I do, I'm often surprised by the answers. I can very confidently say that this pain in the right shoulder after lifting is not a sign of an impending heart attack, or this bump on the shin is not a deep vein thrombosis.

Only when I have explored can I reassure-and, if I can do this effectively, I'm not guarding a gate but preventing an unnecessary journey.

Competing interests: See www.bmj.com/about-bmj/freelance-contributors. Provenance and peer review: Commissioned; not externally peer reviewed.

1 Sripa P, Hayhoe B, Garg P, Majeed A, Greenfield G. Impact of GP gatekeeping on quality of care, and health outcomes, use, and expenditure: a systematic review. Br J Gen Pract 2019;69:e294-303. 10.3399/bjgp19X702209. 30910875

2 World Health Organization Europe. What are the advantages and disadvantages of restructuring a health care system to be more focused on primary care services? 2004. http://www.euro.who.int/en/health-topics/Health-systems/primary-health-care/publications/ pre-2009/what-are-the-advantages-and-disadvantages-of-restructuring-a-health-caresystem-to-be-more-focused-on-primary-care-services-whoeurope-2004.

3 Wilkinson E. CCGs continue to offer cash rewards for GPs to cut referrals. Pulse 2019 Mar 26. http://www.pulsetoday.co.uk/news/hot-topics/cash-for-cuts/ccgs-continue-to-offercash-rewards-for-gps-to-cut-referrals/20038448.article. (Login needed.)

Published by the BMJ Publishing Group Limited. For permission to use (where not already granted under a licence) please go to http://group.bmj.com/group/rights-licensing/ permissions 